\title{
Different Patterns of Risk Reducing Decisions in Affected or Unaffected BRCA Pathogenic Variant Carriers
}

\author{
Eun-Gyeong Lee, $\mathrm{MD}^{1}$ \\ Hyok Jo Kang, MD ${ }^{1}$ \\ Myong Cheol Lim, MD, PhD23,4 \\ Boyoung Park, MD, PhD2 \\ Soo Jin Park, MD ${ }^{1}$ \\ So-Youn Jung, MD, PhD' \\ Seeyoun Lee, MD, $P h D^{1}$ \\ Han-Sung Kang, MD, PhD ${ }^{1}$ \\ Sang-Yoon Park, MD, $\mathrm{Ph} \mathrm{D}^{3,5}$ \\ Boram Park, MS ${ }^{6}$ \\ Jungnam Joo, $\mathrm{PhD}^{6}$ \\ Jai Hong Han, MD ${ }^{1}$ \\ Sun-Young Kong, MD, PhD2,7 \\ Eun Sook Lee, MD, PhD',2
}

*A list author's affiliations appears at the end of the paper.

Correspondence: Eun Sook Lee, MD, PhD

Center for Breast Cancer, Research Institute and Hospital National Cancer Center, 323 Ilsan-ro, Ilsandong-gu, Goyang 10408, Korea

Tel: 82-31-920-1510

Fax: 82-31-920-1511

E-mail: eslee@ncc.re.kr

Co-correspondence: Sun-Young Kong, MD, PhD Graduate School of Cancer Science and Policy,

Genetic Counselling Clinics, Hospital,

National Cancer Center, 323 Ilsan-ro,

Ilsandong-gu, Goyang 10408, Korea

Tel: 82-31-920-1735

Fax: 82-31-920-1268

E-mail: ksy@ncc.re.kr

Received February 1, 2018

Accepted May 2, 2018

Published Online May 4, 2018

\section{Purpose}

The purpose of this study was to investigate decision patterns to reduce the risks of BRCArelated breast and gynecologic cancers in carriers of BRCA pathogenic variants. We found a change in risk-reducing (RR) management patterns after December 2012, when the National Health Insurance System (NHIS) of Korea began to pay for BRCA testing and riskreducing salpingo-oophorectomy (RRSO) in pathogenic-variant carriers.

\section{Materials and Methods}

The study group consisted of 992 patients, including 705 with breast cancer (BC), 23 with ovarian cancer $(\mathrm{OC}), 10$ with both, and 254 relatives of high-risk patients who underwent BRCA testing at the National Cancer Center of Korea from January 2008 to December 2016.We analyzed patterns of and factors in RR management.

\section{Results}

Of the 992 patients, 220 (22.2\%) were carriers of BRCA pathogenic variants. About $92.3 \%$ $(203 / 220)$ had a family history of BC and/or OC, which significantly differed between BRCA1 and BRCA2 carriers $(p<0.001)$. All 41 male carriers chose surveillance. Of the 179 female carriers, 59 of the 83 carriers (71.1\%) with BC and the 39 of 79 unaffected carriers (49.4\%) underwent RR management. None of the carriers affected with OC underwent RR management. Of the management types, RRSO had the highest rate $(42.5 \%)$ of patient choice. The rate of RR surgery was significantly higher after 2013 than before 2013 (46.3\% [74/160] vs. $31.6 \%$ [6/19], $p<0.001)$.

\section{Conclusion}

RRSO was the preferred management for carriers of BRCA pathogenic variants. The most important factors in treatment choice were NHIS reimbursement and/or the severity of illness. 


\section{Introduction}

Pathogenic variants of $B R C A 1$ and $B R C A 2$ result in hereditary breast-ovarian cancer syndrome (HBOS) in affected persons [1]. Activating mutations in BRCA1 and BRCA2 are present in approximately $16 \%-25 \%$ of hereditary breast cancers (BCs) [2,3], 5\%-10\% of all BCs [4], and $15 \%$ of ovarian cancers (OC) [5]. BRCA pathogenic variants are also associated with an increased risk of developing any invasive cancer [6]. Risk-reducing mastectomy (RRM) reduces the lifetime risk of BC diagnosis [7]; and salpingo-oophorectomy is the single most effective method to prevent ovarian and fallopian tube cancer in women with a BRCA pathogenic variant $[8,9]$. Current National Comprehensive Cancer Network (NCCN) guidelines recommend risk-reducing salpingooophorectomy (RRSO) at age 35-45 years and after completion of child bearing. Patients who undergo RRM can select from various procedural options, each associated with a different risk of subsequently developing $\mathrm{BC}$, and reconstruction options [10]. In Western countries, RRSO was the approach of choice to reduce the OC risk in about $50 \%-70 \%$ of patients with pathogenic variants of BRCA1 and BRCA2 undergoing risk-reducing (RR) management [3,11]. However, there are few reports about RR management in Asia. In December 2012, the National Health Insurance System (NHIS) of Korea approved reimbursement of BRCA testing and RRSO in patients suspected of having a BRCA1/2 mutation. The patterns of RR management began changing after NHIS instituted its new policy. However, RR management decision-making remains difficult because of various individual factors.

A recent retrospective study revealed that the rate of RRSO among female carriers of BRCA mutations in Korea was affected by the presence of amenorrhea and consultation with gynecologic oncologists [12]. To date, the types of RR management in Korean carriers of BRCA pathogenic variants, including unaffected pathogenic variant carriers, have not been evaluated. To address this gap in research, this study was designed to identify RR management patterns in Korean carriers of BRCA1 and BRCA2 pathogenic variants.

\section{Materials and Methods}

\section{Study population}

This study was designed as a retrospective cohort study. We evaluated the medical records of 992 consecutive patients, including those with breast and/or OC as well as relatives of high-risk patients, who underwent $B R C A$ testing from January 2008 to December 2016 at the National Cancer Center of Korea (Goyang, Korea). Based on the standards of the National Medical Insurance Reimbursement in Korea, patients with BC and OC and a family history of BC or OC, early onset $\mathrm{BC}$ (diagnosed at age $\leq 40$ years), bilateral $\mathrm{BC}$, both $\mathrm{BC}$ and $\mathrm{OC}$, male $\mathrm{BC}$, or multi-organ cancer are recommended to undergo testing for $B R C A 1 / 2$ pathogenic variants.

\section{Genetic testing and RR management}

BRCA mutations were determined by direct gene sequencing. Some patients without pathogenic variants who agreed to additional testing were further evaluated by BRCA deletion/duplication analysis using multiplex ligation-dependent probe amplification (MLPA) kits. Of the 992 individuals who underwent BRCA testing, 220 (22.2\%) had BRCA pathogenic variants, including $125(12.6 \%)$ with $B R C A 1$ variants and $95(9.6 \%)$ with BRCA2 variants (Fig. 1).

After patients with $B R C A 1 / 2$ pathogenic variants were identified by genetic testing, the carriers met with a genetic counselor or various clinical experts, such as surgeons, oncologists specializing in BC, or gynecologic oncologists. Carriers were advised about appropriate risk reduction options according to carriers' preference, disease severity, and expert advice on RR management.

RR management methods presented to carriers included RR surgery and chemoprevention. Chemoprevention included oral contraceptives, olaparib for patients with $\mathrm{OC}$, and tamoxifen for hormone-receptor positive patients with BC. RR surgery included RRM and RRSO. For carriers who elected surveillance, BC and OC screening at 6-month intervals was recommended. Of the $220 \mathrm{BRCA}$ pathogenic-variant carriers, 98 (44.5\%) underwent RR management.

\section{Statistical analysis}

Statistical analysis was performed using SAS 9.4 software (SAS Institute Inc., Cary, NC). The distribution of clinicopathological characteristics in BRCA1 and BRCA2 pathogenic-variant carriers were compared, and the factors affecting RR management in the female carriers were assessed appropriately, depending on the characteristics of each variable. Male carrier patients were excluded from the analysis of RR management patterns. Continuous variables were analyzed using Student's t test and represented as the mean \pm standard deviation, whereas categorical variables were analyzed using Pearson's chi-square test or Fisher exact test, as appropriate, and represented as frequency and percentages. Statistical significance was defined as $p<0.05$. 


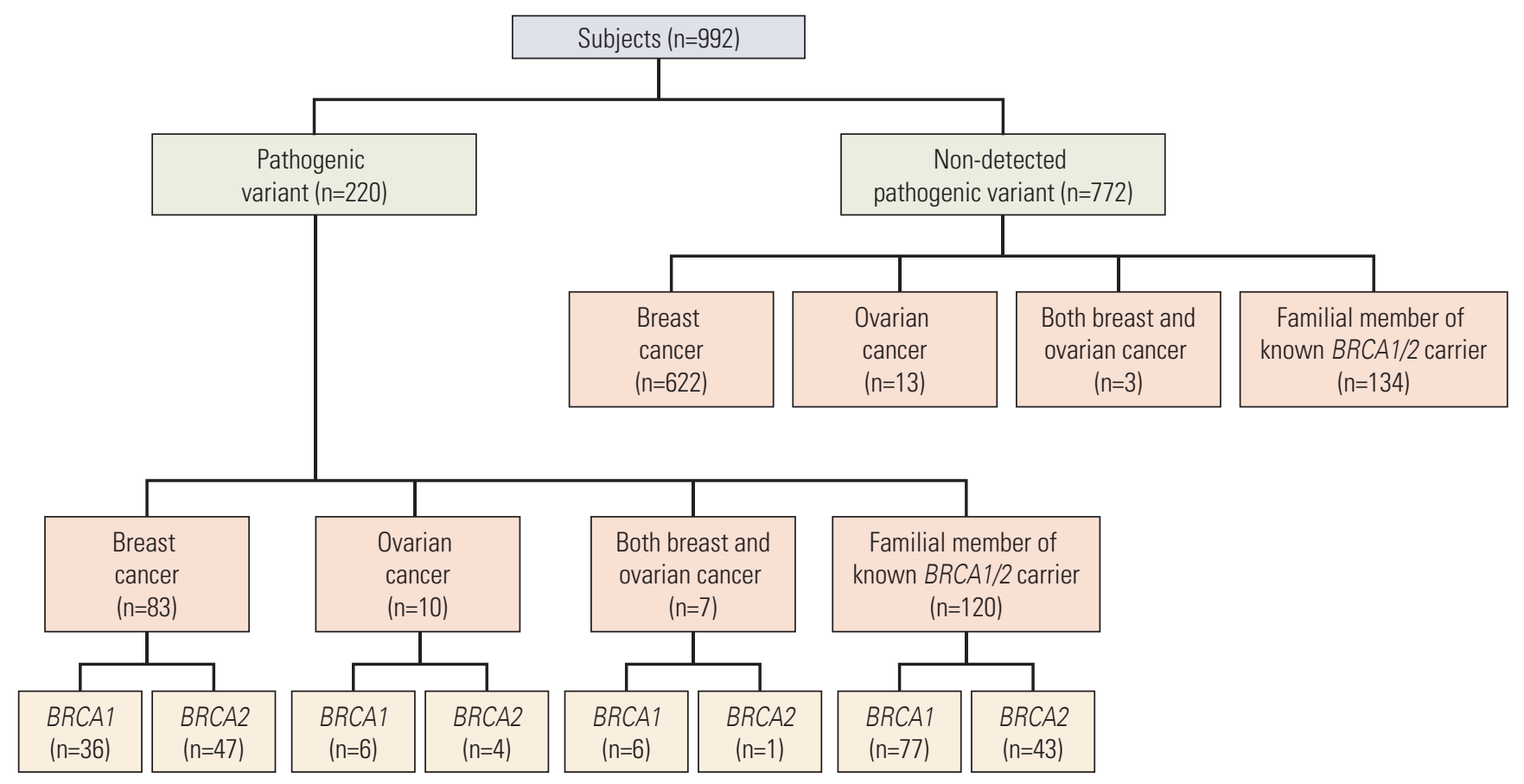

Fig. 1. Flow diagram of study subjects. Genetic testing included direct sequencing and multiple ligation-dependent probe amplification analysis. A total of 220 carriers of pathogenic variants, including 125 with BRCA1 gene variants and 95 with $B R C A 2$ gene variants, were identified.

\section{Ethical statement}

The informed consent was waived and this study was approved by the Institutional Review Board of the Korean National Cancer Center (Goyang, Korea; approval no. NCC2017-0219).

\section{Results}

\section{Comparison of $B R C A 1$ vs. $B R C A 2$}

Of the 220 carriers of $B R C A$ pathogenic variants, 125 had $B R C A 1$ mutations, and 95 had BRCA2 mutations. Table 1 shows the clinical and pathological characteristics of these patients. The mean ages of these two groups were 39.3 and 43.7 years, respectively $(\mathrm{p}=0.009)$. The 220 carriers included 179 women and 41 men $(\mathrm{p}=0.100)$. None of these carriers had mutations in both the BRCA1 and BRCA2 genes.

The 220 individuals consisted of 83 patients with BC, 10 with OC, and seven with both, as well as 120 unaffected carriers $(\mathrm{p}=0.010)$. Approximately $92.3 \%(203 / 220)$ had a family history of BC and/or OC, including 117 (93.6\%) of the 125 with BRCA1 mutations and $86(90.5 \%)$ of the 95 with BRCA2 mutations $(\mathrm{p}<0.001)$. The rate of family OC history was significantly higher ( $50.4 \%$ vs. $22.1 \%$ ) and the rate of family BC history significantly lower $(19.2 \%$ vs. $56.8 \%)$ in carriers of $B R C A 1$ than in carriers of $B R C A 2$ pathogenic variants. The rate of family $B C$ history was also significantly lower in carriers of $B R C A 1$ than in carriers of $B R C A 2$ pathogenic variants with BC (44.4\% vs. 78.7\%, $\mathrm{p}=0.003)$. However, rates of early onset and bilateral $\mathrm{BC}$, as well as stage of $\mathrm{BC}$, did not differ significantly in carriers of $B R C A 1$ and $B R C A 2$ pathogenic variants. The most common $B C$ subtypes in carriers of $B R C A 1$ and BRCA2 mutations were basal-like $(72.2 \%$ vs. $21.3 \%)$ and luminal A type (19.4\% vs. $70.2 \%)$, respectively $(\mathrm{p}<0.001)$. The percentages of carriers of $B R C A 1$ and $B R C A 2$ pathogenic variants did not differ significantly in patients with OC. In unaffected carriers of BRCA pathogenic variants, the rate of family $B C$ history was significantly higher in carriers of $B R C A 2$ than in carriers of $B R C A 1$ pathogenic variants (3.9\% vs. $39.5 \%)$, whereas the rate of familial OC history was significantly higher in BRCA1 than in BRCA2 variants $(68.8 \%$ vs. $37.2 \%, \mathrm{p}<0.001)$. 
Table 1. Overall characteristics of $B R C A$ pathogenic variant carriers

\begin{tabular}{|c|c|c|c|c|}
\hline Clinicopathological characteristic & Total & BRCA1 & BRCA2 & p-value \\
\hline$B R C A$ pathogenic variant carriers & 220 & 125 & 95 & \\
\hline Age (yr) & $41.23 \pm 12.59$ & $39.32 \pm 12.83$ & $43.75 \pm 11.86$ & 0.010 \\
\hline \multicolumn{5}{|l|}{ Sex } \\
\hline Male & 41 & $28(22.4)$ & $13(13.7)$ & 0.100 \\
\hline Female & 179 & $97(77.6)$ & $82(86.3)$ & \\
\hline \multicolumn{5}{|l|}{ Familial history } \\
\hline None & 17 & $8(6.4)$ & $9(9.5)$ & $<0.001$ \\
\hline Breast cancer & 78 & $24(19.2)$ & $54(56.8)$ & \\
\hline Ovarian cancer & 84 & $63(50.4)$ & $21(22.1)$ & \\
\hline Both breast and ovarian cancer & 41 & $30(24.0)$ & $11(11.6)$ & \\
\hline Affected carriers with breast cancer & 83 & 36 & 47 & \\
\hline Age (yr) & $45.01 \pm 8.92$ & $43.78 \pm 8.61$ & $45.96 \pm 9.14$ & 0.273 \\
\hline \multicolumn{5}{|l|}{ Familial history } \\
\hline None & 14 & $7(19.4)$ & $7(14.9)$ & 0.003 \\
\hline Breast cancer & 53 & $16(44.4)$ & 37 (78.7) & \\
\hline Ovarian cancer & 8 & $6(16.7)$ & $2(4.3)$ & \\
\hline Both breast and ovarian cancer & 8 & $7(19.4)$ & $1(2.1)$ & \\
\hline \multicolumn{5}{|l|}{ Early onset breast cancer } \\
\hline No & 69 & $28(77.8)$ & $41(87.2)$ & 0.254 \\
\hline Yes & 14 & $8(22.2)$ & $6(12.8)$ & \\
\hline \multicolumn{5}{|l|}{ Bilaterality of breast cancer } \\
\hline No & 70 & $33(91.7)$ & 37 (78.7) & 0.108 \\
\hline Yes & 13 & $3(8.3)$ & $10(21.3)$ & \\
\hline \multicolumn{5}{|l|}{ Stage of breast cancer } \\
\hline Tis & 3 & $2(5.6)$ & $1(2.1)$ & 0.602 \\
\hline I & 32 & $14(38.9)$ & $18(38.3)$ & \\
\hline II & 41 & $16(44.4)$ & $25(53.2)$ & \\
\hline III & 6 & $4(11.1)$ & $2(4.3)$ & \\
\hline IV & 1 & 0 & $1(2.1)$ & \\
\hline \multicolumn{5}{|l|}{ Subtypes of breast cancer } \\
\hline Luminal A & 40 & $7(19.4)$ & $33(70.2)$ & $<0.001$ \\
\hline Luminal B & 5 & $2(5.6)$ & $3(6.4)$ & \\
\hline HER2 & 2 & $1(2.8)$ & $1(2.1)$ & \\
\hline Basal & 36 & $26(72.2)$ & $10(21.3)$ & \\
\hline Affected carriers with ovary cancer & 10 & 6 & 4 & \\
\hline Age (yr) & $53 \pm 6.82$ & $52.33 \pm 8.57$ & $54 \pm 3.83$ & 0.728 \\
\hline \multicolumn{5}{|l|}{ Stage of ovarian cancer } \\
\hline I & 2 & $1(16.7)$ & $1(25.0)$ & 0.886 \\
\hline II & 2 & $1(16.7)$ & $1(25.0)$ & \\
\hline III & 2 & $2(33.3)$ & 0 & \\
\hline IV & 3 & $1(16.7)$ & $2(50.0)$ & \\
\hline Unknown & 1 & $1(16.7)$ & 0 & \\
\hline \multicolumn{5}{|l|}{ Familial history } \\
\hline None & 2 & 0 & $2(50.0)$ & 0.333 \\
\hline Breast cancer & 1 & $1(16.7)$ & 0 & \\
\hline Ovarian cancer & 5 & $3(50.0)$ & $2(50.0)$ & \\
\hline Both breast and ovarian cancer & 2 & $2(33.3)$ & 0 & \\
\hline
\end{tabular}

(Continued to the next page) 
Table 1. Continued

\begin{tabular}{lcccc} 
Clinicopathological characteristic & Total & BRCA1 & BRCA2 & p-value \\
Unaffected carriers & 120 & 77 & 43 & \\
Age (yr) & $37 \pm 13.6$ & $35.23 \pm 13.22$ & $40.16 \pm 13.84$ & 0.057 \\
\hline Familial history & & & & \\
$\quad$ Breast cancer & 20 & $3(3.9)$ & $17(39.5)$ & $<0.001$ \\
$\quad$ Ovarian cancer & 70 & $53(68.8)$ & $16(37.2)$ & \\
\hline Both breast and ovarian cancer & 30 & $21(27.3)$ & $9(20.9)$ & \\
\hline
\end{tabular}

Values are presented as the mean \pm standard deviation or the number $(\%)$.
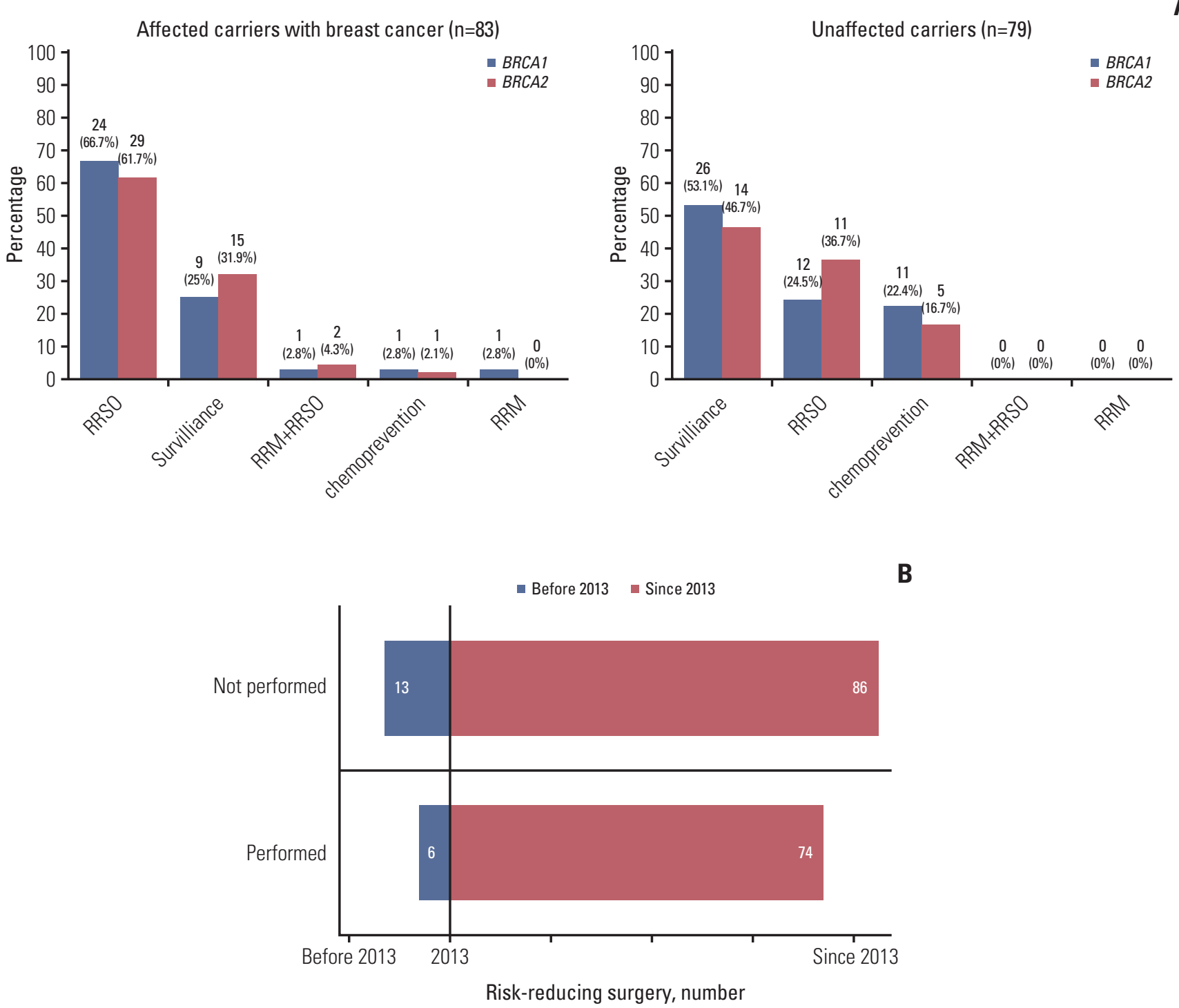

Fig. 2. Types of risk-reducing management applied to female $B R C A 1 / 2$ pathogenic variant carriers over time. (A) Types of risk-reducing management chosen by affected female $B R C A 1 / 2$ pathogenic-variant carriers with breast cancer and by unaffected carriers. (B) Numbers of women who underwent risk-reducing surgery before and after 2013, the year National Health Insurance System began reimbursing for BRCA testing and risk-reducing salpingo-oophorectomy in pathogenic-variant carriers. RRSO, riskreducing salpingo-oophorectomy; RRM, risk-reducing mastectomy. 
Table 2. Factors affecting risk-reducing management patterns in female $B R C A 1 / 2$ pathogenic-variant carriers

\begin{tabular}{|c|c|c|c|c|}
\hline Factor & $\begin{array}{c}\text { Total } \\
\text { number }\end{array}$ & $\begin{array}{l}\text { Not performed } \\
\text { RR management }\end{array}$ & $\begin{array}{c}\text { Performed } \\
\text { RR management }\end{array}$ & p-value \\
\hline$B R C A 1 / 2$ pathogenic variant carriers & 179 & 81 & 98 & \\
\hline Age (yr) & $43.15 \pm 12.26$ & $43.58 \pm 13.32$ & $42.79 \pm 11.37$ & 0.667 \\
\hline \multicolumn{5}{|l|}{$B R C A$ mutation } \\
\hline$B R C A 1$ & 97 & $47(58.0)$ & $50(51.0)$ & 0.349 \\
\hline$B R C A 2$ & 82 & $34(42.0)$ & $48(49.0)$ & \\
\hline \multicolumn{5}{|l|}{ Type of carriers } \\
\hline Affected carriers with breast cancer & 83 & $24(29.6)$ & $59(60.2)$ & $<0.001$ \\
\hline Affected carriers with ovary cancer & 10 & $10(12.4)$ & 0 & \\
\hline Affected carriers with both cancer & 7 & $7(8.6)$ & 0 & \\
\hline Unaffected carriers & 79 & $40(49.4)$ & $39(39.8)$ & \\
\hline \multicolumn{5}{|l|}{ Familial history } \\
\hline None & 17 & $8(9.9)$ & $9(9.2)$ & 0.249 \\
\hline Breast cancer & 72 & $27(33.3)$ & $45(45.9)$ & \\
\hline Ovarian cancer & 60 & $33(40.7)$ & $27(27.6)$ & \\
\hline Both breast and ovarian cancer & 30 & $13(16.1)$ & $17(17.3)$ & \\
\hline Affected carriers with breast cancer & 83 & 24 & 59 & \\
\hline Age (yr) & $45.01 \pm 8.92$ & $41.13 \pm 7.80$ & $46.59 \pm 8.93$ & 0.011 \\
\hline \multicolumn{5}{|l|}{ Familial history } \\
\hline None & 14 & $5(20.8)$ & $9(15.3)$ & 0.853 \\
\hline Breast cancer & 53 & $14(58.3)$ & $39(66.1)$ & \\
\hline Ovarian cancer & 8 & $3(12.5)$ & $5(8.5)$ & \\
\hline Both breast and ovarian cancer & 8 & $2(8.3)$ & $6(10.2)$ & \\
\hline \multicolumn{5}{|l|}{ Early onset breast cancer } \\
\hline No & 69 & $16(66.7)$ & $53(89.8)$ & 0.020 \\
\hline Yes & 14 & $8(33.3)$ & $6(10.2)$ & \\
\hline \multicolumn{5}{|l|}{ Bilaterality of breast cancer } \\
\hline No & 70 & $21(87.5)$ & $49(83.1)$ & 0.748 \\
\hline Yes & 13 & $3(12.5)$ & $10(17)$ & \\
\hline \multicolumn{5}{|l|}{ Stage of breast cancer } \\
\hline Tis & 3 & 0 & $3(5.1)$ & 0.489 \\
\hline I & 32 & $9(37.5)$ & $23(39)$ & \\
\hline II & 41 & $13(54.2)$ & $28(47.5)$ & \\
\hline III & 6 & $1(4.2)$ & $5(8.5)$ & \\
\hline IV & 1 & $1(4.2)$ & 0 & \\
\hline \multicolumn{5}{|l|}{ Subtypes of breast cancer } \\
\hline Luminal A & 40 & $11(45.8)$ & $29(49.2)$ & 0.930 \\
\hline Luminal B & 5 & $1(4.2)$ & $4(6.8)$ & \\
\hline HER2 & 2 & 0 & $2(3.4)$ & \\
\hline Basal & 36 & $12(50)$ & $24(40.7)$ & \\
\hline Unaffected carriers & 79 & 40 & 39 & \\
\hline Age (yr) & $39.14 \pm 14.56$ & $41.20 \pm 16.34$ & $37.03 \pm 12.33$ & 0.205 \\
\hline \multicolumn{5}{|l|}{ Familial history } \\
\hline Breast cancer & 14 & $8(20.0)$ & $6(15.4)$ & 0.659 \\
\hline Ovarian cancer & 46 & $24(60.0)$ & $22(56.4)$ & \\
\hline Both breast and ovarian cancer & 19 & $8(20.0)$ & $11(28.2)$ & \\
\hline
\end{tabular}

Values are presented as the mean \pm standard deviation or the number $(\%)$. RR, risk-reducing. 


\section{RR management of female carriers of $B R C A 1 / 2$ patho- genic variants}

All 41 male carriers chose surveillance. RR management patterns in female carriers of $B R C A 1 / 2$ pathogenic variants are presented in Fig. 2. Of these 179 women, 98 (54.7\%) underwent RR management, including $18(10.1 \%)$ who received chemoprevention and $80(44.7 \%)$ who underwent risk-reducing surgery (RRS), including RRSO in 76 patients, RRM in one, and both in three. The remaining 81 patients $(45.3 \%)$ chose intensive surveillance, including both BC and OC patients. Of the female BRCA1/2 pathogenic-variant carriers with BC, $59(71.1 \%)$ underwent RR management, including RRSO in 53 patients, contralateral RRM in one, both in three, and chemoprevention in two ( $\mathrm{p}=0.8497)$. The distribution of $\mathrm{BC}$ subtype in the 56 affected carriers with $\mathrm{BC}$ who underwent RRSO was $51.8 \%$ luminal A type, $7.1 \%$ luminal B type, $3.6 \%$ HER-2 type, and $37.5 \%$ basal type.

None of the affected carriers with OC underwent RR management for BC. Of the 79 unaffected female carriers, 39 $(49.4 \%)$ received RR management, including $23(29.1 \%)$ who underwent RRSO and 16 (20.3\%) who received chemoprevention $(p=0.495)$.

Insurance reimbursement started in 2013. The numbers of carriers of pathogenic variants detected (160 vs. 19) and the percentage who underwent RRS (46.3\% [74/160] vs. 31.6\% [6/19], $\mathrm{p}<0.001$ ) were significantly higher after 2013 than before 2013 (Fig. 2B).

\section{Factors affecting RR management of female carriers of $B R C A 1 / 2$ pathogenic variants}

The type of female carriers was significantly associated with RR management $(\mathrm{p}<0.001)$ (Table 2$)$. In affected female carriers with $\mathrm{BC}$, older age was significantly associated with $R R$ management $(\mathrm{p}=0.011)$. However, in unaffected carriers, age, type of $B R C A$ pathogenic variant, and family history were not significantly associated with RR management.

\section{Discussion}

In the current study, we investigated RR management patterns in BRCA1 and BRCA2 pathogenic-variant carriers, including both affected and unaffected carriers. The prevalence of these pathogenic varinats was associated with both familial and personal factors. Carriers of pathogenic variants with both familial and personal factors were at much higher risk of cancer [13]. RR management in carriers of $B R C A$ mutations has been studied more in Western than in Asian populations $[3,14]$. To our knowledge, this study involved the largest number of Asian BRCA pathogenic-variant carriers managed by RR approaches.

We found that older age of affected carriers with BC was significantly associated with RR management. Interestingly, in unaffected carriers, age, family history, and type of $B R C A$ pathogenic variant were not associated with the decision to undergo RR management. The results showed that carriers may consider whether to undergo RR management differently depending on the type of carrier. Although a high percentage of $B R C A$ carriers in a population-based health system underwent RRSO, these women did not undergo RRSO by the age recommended by the NCCN [14]. Older age was found to be significantly associated with an increase in RRSO rate [12]. According to the World Health Organization, the fertility rates of Korean women are lower than in other populations. As the average age at the first marriage increased in Korea, so has the age at the first childbirth. This may explain the association we found between age and decision to undergo RR management.

The prevalence of OC in our population was low. However, $\mathrm{OC}$ tends to be diagnosed at an advanced stage and has a poorer survival rate than BC [15]. Moreover, carriers of $B R C A$ pathogenic variants were found to worry about developing OC $[16,17]$. Our findings were similar: the mean age of RR management in carriers with $\mathrm{BC}$ was 46 years, and the frequency of RR management was lower in patients with early onset $\mathrm{BC}$. The rate of RRSO was higher in unaffected carriers with a family history of OC than in those with a familial history of BC. Assessment of survival in our population showed that four (4.8\%) affected carriers with $\mathrm{BC}$, one $(10.0 \%)$ affected carrier with OC, and one (14.3\%) affected carrier with both died. Most affected carriers with OC had advanced stage disease and were being treated with adjuvant chemotherapy. A review of pathologic reports of patients who underwent RR surgery showed that no woman who underwent RRM was diagnosed with $B C$, whereas three women who underwent RRSO were diagnosed with ovarian, fallopian tube, or peritoneal cancer and required additional treatment.

$\mathrm{BC}$ has a better prognosis than OC. BC screening is easier and can detect early cancerous lesions. With recent advancements, reconstructive surgery after mastectomy has a low rate of complications and increases patient satisfaction $[18,19]$. However, RRM may destroy body image and be costly, as it may not be reimbursed by insurance. A study of women carriers of $B R C A$ pathogenic variants showed that those who opted for RRM were significantly more satisfied with their decision than those who did not undergo surgery [20]. A previous study showed RRM performed within 5 years was not cost effective when compared with BC screening for most $B R C A$ pathogenic-variant carriers with $O C$ [21]. 
Interestingly, we found that RRM was less preferred by these carriers, indicating that RRM must be chosen by patients.

In Korea, the detection of pathogenic variants and the performance of RRSs have changed over time. Since 2013, the annual number of individuals with $B R C A$ pathogenic variants has increased, as has the percentage undergoing surgery. These increases are largely due to insurance reimbursement for RRSO and genetic testing of family members by the NHIS in Korea. Since October 2017, in carriers with BC, RRM of the contralateral breast and reconstruction are also covered. Future insurance coverage changes may further affect the patterns of RRSs in BRCA pathogenic-variant carriers. Another possible factor in the change of RR management patterns is the "Angelina Jolie effect" after the movie star Angelina Jolie, who is a BRCA pathogenic-variant carrier, underwent RRM despite being unaffected [22,23]. This increased public attention to HBOS and RR management [24]. In RR management, RRSO is a safe and simple surgery. Recently, embryonic natural orifice transumbilical endoscopic surgery is performed efficiently with good cosmetic outcome [25]. A meta-analysis of other studies on the efficacy of RRSO reported hazard ratios of 0.21 (95\% confidence interval [CI], 0.12 to 0.39 ) for onset of ovarian and fallopian tube cancer and 0.49 (95\% CI, 0.37 to 0.65 ) for onset of BC, indicating that the risk of developing these cancers was reduced following RRSO [26]. A third reason for the increase was the opening of genetic counseling clinics, with active counselors and researchers $[27,28]$. Our study showed that genetic testing and consulting have grown rapidly since 2013. Nevertheless, in this study, unaffected carriers paid less attention to RR management, with about 36\% lost to followup. Decisions on RR management may depend on the various factors, including family history, awareness of disease, the individual's environment, insurance reimbursement, and age at detection of a BRCA mutation [29]. Improved education and genetic counseling support throughout the decisionmaking process have been found to enhance carriers' overall levels of satisfaction [30].

Our study had several limitations, despite assessing a greater number of patients with RR management than in pre- viously published studies. First, this study was a single-center retrospective study. Second, we could not perform MLPA tests on all non-carriers of BRCA pathogenic variants. Third, this study examined a heterogeneous cohort. Future multicenter studies are needed to provide more information on patterns of RR management.

In this study, the older affected carriers with BC underwent more RR management, and RRSO was preferred to RRM by both affected carriers with BC and unaffected carriers. This may have been due to the severity of illness and to RRSO being the only RR strategy reimbursed by the NHIS. Further long-term follow-up prospective studies of RR management are needed, including investigations into the effects of genetic counseling, insurance payments, and social media marketing.

\section{Conflicts of Interest}

Conflict of interest relevant to this article was not reported.

\section{Acknowledgments}

This study was supported by grants from the National Cancer Center of Korea (Nos. 1710171 \& 1710172). We thank Kyungju Lee and Heesang Eum, who provided support for this study.

\section{Author Details}

${ }^{1}$ Center for Breast Cancer, Research Institute and Hospital, National Cancer Center, Goyang, ${ }^{2}$ Graduate School of Cancer Science and Policy, National Cancer Center, Goyang, ${ }^{3}$ Center for Uterine Cancer, Research Institute and Hospital, National Cancer Center, Goyang, ${ }^{4}$ Cancer Healthcare Research Branch, Research Institute, National Cancer Center, Goyang, ${ }^{5}$ Common Cancer Branch, Research Institute, National Cancer Center, Goyang, 'Biometrics Research Branch, Division of Cancer Epidemiology and Management, Research Institute, National Cancer Center, Goyang, ${ }^{7}$ Department of Laboratory Medicine \& Genetic Counselling Clinics, Hospital, National Cancer Center, Goyang, Korea

\section{References}

1. Claus EB, Schildkraut JM, Thompson WD, Risch NJ. The genetic attributable risk of breast and ovarian cancer. Cancer. 1996;77:2318-24.

2. Easton DF. How many more breast cancer predisposition genes are there? Breast Cancer Res. 1999;1:14-7.

3. Beattie MS, Crawford B, Lin F, Vittinghoff E, Ziegler J. Uptake, time course, and predictors of risk-reducing surgeries in BRCA carriers. Genet Test Mol Biomarkers. 2009;13:51-6.

4. Campeau PM, Foulkes WD, Tischkowitz MD. Hereditary breast cancer: new genetic developments, new therapeutic avenues. Hum Genet. 2008;124:31-42.

5. Pal T, Permuth-Wey J, Betts JA, Krischer JP, Fiorica J, Arango 
$\mathrm{H}$, et al. BRCA1 and BRCA2 mutations account for a large proportion of ovarian carcinoma cases. Cancer. 2005;104:2807-16.

6. Friedenson B. BRCA1 and BRCA2 pathways and the risk of cancers other than breast or ovarian. MedGenMed. 2005;7:60.

7. Meijers-Heijboer H, van Geel B, van Putten WL, Henzen-Logmans SC, Seynaeve C, Menke-Pluymers MB, et al. Breast cancer after prophylactic bilateral mastectomy in women with a BRCA1 or BRCA2 mutation. N Engl J Med. 2001;345:159-64.

8. Greene MH, Mai PL, Schwartz PE. Does bilateral salpingectomy with ovarian retention warrant consideration as a temporary bridge to risk-reducing bilateral oophorectomy in BRCA1/ 2 mutation carriers? Am J Obstet Gynecol. 2011;204: 19.e1-6.

9. Morris JL, Gordon OK. Positive results: making the best decisions when you're at high risk for breast or ovarian cancer. Amherst, NY: Prometheus Books; 2010.

10. Daly MB, Pilarski R, Axilbund JE, Berry M, Buys SS, Crawford $B$, et al. Genetic/familial high-risk assessment: breast and ovarian, version 2.2015. J Natl Compr Canc Netw. 2016;14:15362.

11. Schwartz MD, Isaacs C, Graves KD, Poggi E, Peshkin BN, Gell $\mathrm{C}$, et al. Long-term outcomes of BRCA1/BRCA2 testing: risk reduction and surveillance. Cancer. 2012;118:510-7.

12. Kim SI, Lim MC, Lee DO, Kong SY, Seo SS, Kang S, et al. Uptake of risk-reducing salpingo-oophorectomy among female BRCA mutation carriers: experience at the National Cancer Center of Korea. J Cancer Res Clin Oncol. 2016;142:33340.

13. Fu R, Harris EL, Helfand M, Nelson HD. Estimating risk of breast cancer in carriers of BRCA1 and BRCA2 mutations: a meta-analytic approach. Stat Med. 2007;26:1775-87.

14. Garcia C, Wendt J, Lyon L, Jones J, Littell RD, Armstrong MA, et al. Risk management options elected by women after testing positive for a BRCA mutation. Gynecol Oncol. 2014;132:42833.

15. Choi MC, Lim MC, Lee M, Kim MK, Suh DH, Song YJ, et al. Practice patterns of hereditary ovarian cancer management in Korea. Int J Gynecol Cancer. 2017;27:895-9.

16. Lim MC, Moon EK, Shin A, Jung KW, Won YJ, Seo SS, et al. Incidence of cervical, endometrial, and ovarian cancer in Korea, 1999-2010. J Gynecol Oncol. 2013;24:298-302.

17. Watson M, Foster C, Eeles R, Eccles D, Ashley S, Davidson R, et al. Psychosocial impact of breast/ovarian (BRCA1/2) cancer-predictive genetic testing in a UK multi-centre clinical cohort. Br J Cancer. 2004;91:1787-94.

18. Del Corral GA, Wes AM, Fischer JP, Serletti JM, Wu LC. Outcomes and cost analysis in high-risk patients undergoing simultaneous free flap breast reconstruction and gynecologic procedures. Ann Plast Surg. 2015;75:534-8.

19. Hagen AI, Maehle L, Veda N, Vetti HH, Stormorken A, Ludvigsen $\mathrm{T}$, et al. Risk reducing mastectomy, breast reconstruction and patient satisfaction in Norwegian BRCA1/2 mutation carriers. Breast. 2014;23:38-43.

20. Hooker GW, King L, Vanhusen L, Graves K, Peshkin BN, Isaacs $\mathrm{C}$, et al. Long-term satisfaction and quality of life following risk reducing surgery in BRCA1/2 mutation carriers. Hered Cancer Clin Pract. 2014;12:9.

21. Gamble C, Havrilesky LJ, Myers ER, Chino JP, Hollenbeck S, Plichta JK, et al. Cost effectiveness of risk-reducing mastectomy versus surveillance in BRCA mutation carriers with a history of ovarian cancer. Ann Surg Oncol. 2017;24:3116-23.

22. Evans DG, Barwell J, Eccles DM, Collins A, Izatt L, Jacobs C, et al. The Angelina Jolie effect: how high celebrity profile can have a major impact on provision of cancer related services. Breast Cancer Res. 2014;16:442.

23. Freedman R, Mountain H, Karina D, Schofield L. A retrospective exploration of the impact of the 'Angelina Jolie Effect' on the single state-wide familial cancer program in Perth, Western Australia. J Genet Couns. 2017;26:52-62.

24. Evans DG, Wisely J, Clancy T, Lalloo F, Wilson M, Johnson R, et al. Longer term effects of the Angelina Jolie effect: increased risk-reducing mastectomy rates in BRCA carriers and other high-risk women. Breast Cancer Res. 2015;17:143.

25. Lim MC, Kim TJ, Kang S, Bae DS, Park SY, Seo SS. Embryonic natural orifice transumbilical endoscopic surgery (E-NOTES) for adnexal tumors. Surg Endosc. 2009;23:2445-9.

26. Rebbeck TR, Kauff ND, Domchek SM. Meta-analysis of risk reduction estimates associated with risk-reducing salpingooophorectomy in BRCA1 or BRCA2 mutation carriers. J Natl Cancer Inst. 2009;101:80-7.

27. Bando H. Issues of concern in risk assessment, genetic counseling, and genetic testing of younger breast cancer patients in Japan. Breast Cancer. 2014;21:656-63.

28. Eitan R, Michaelson-Cohen R, Levavi H, Beller U. The counseling and management of young healthy BRCA mutation carriers. Int J Gynecol Cancer. 2009;19:1156-9.

29. Kauff ND, Scheuer L, Robson ME, Glogowski E, Kelly B, Barakat $\mathrm{R}$, et al. Insurance reimbursement for risk-reducing mastectomy and oophorectomy in women with BRCA1 or BRCA2 mutations. Genet Med. 2001;3:422-5.

30. Guillem JG, Wood WC, Moley JF, Berchuck A, Karlan BY, Mutch DG, et al. ASCO/SSO review of current role of riskreducing surgery in common hereditary cancer syndromes. Ann Surg Oncol. 2006;13:1296-321. 